\title{
Identification of ignition sources in high pressure enriched gaseous oxygen system incidents using flow chart road map diagram methodology
}

CM Benson, JM Ingram, PF Nolan¹.

Author names and affiliations:

\begin{tabular}{|l|l|l|}
\hline $\begin{array}{l}\text { Claire M Benson } \\
\text { (Corresponding author) }\end{array}$ & $\begin{array}{l}\text { James M Ingram } \\
\text { (deceased) }\end{array}$ \\
\hline bensoncb@Isbu.ac.uk & ingramja@Isbu.ac.uk & esbe-efrg@lsbu.ac.uk \\
\hline
\end{tabular}

All work conducted at:

Explosion \& Fire Research Group,

London South Bank University (School of Engineering),

103 Borough Rd, London, SE1 OAA, UK.

\begin{abstract}
High pressure enriched oxygen is used in a wide number of areas, including aircraft, medical breathing apparatus, and a number of industrial processes including combustion. Unwanted ignition in such systems can cause significant damage to property and danger to life. It is important to gain as much information, and record relevant data for every oxygen incident, enabling both immediate analysis, and post-event evaluations (especially where circumstances are repeated). The lack of clear concise guidance can result in data loss. This work successfully develops investigation 'road maps' as guidance documents for investigators to use, even under difficult \& time pressured conditions. The work demonstrates their usefulness and importance for information collection and the down-selection' or elimination of possible ignition causes through their use with a 'real world' case study. The benefit of this work will be to enable faster and more effective investigation of oxygen incidents, ensuring key details are recorded (benefitting post-accident academic data \& meta-study analysis). The roadmaps can also benefit designers of oxygen systems allowing them to test their designs and operating procedures against specific ignition scenarios.
\end{abstract}

\section{Keywords}

Oxygen systems; Health \& Safety; Incident investigation; Road maps; Fires; explosions; Exothermic reactions; systems analysis

\section{Introduction}

Oxygen is of course vital to sustain life and for this reason oxygen life support systems or breathing apparatuses are used in a wide number of areas, including civil and military aircraft, medical breathing apparatus and hyperbaric chambers, and diving and mountaineering systems. Oxygen is also used industrially to support combustion. Combustion is the rapid runaway oxidation of a fuel, generally following a specific energy input to a fuel/oxidiser mixture. In the case of combustion, the oxidation reaction rate passes a critical point, resulting in energy release and free radical formation that is great

${ }^{1}$ Deceased, August 2014 
enough to bring about further oxidation. Thus a self-perpetuating reaction occurs, while there is both oxygen and fuel to sustain it.

As oxygen is used so extensively, it is often necessary to store and use it at pressures and concentrations well above that of atmospheric. Under these conditions, oxidation reactions occur more readily, and at a faster rate. Some adverse circumstances can result in ignition incidents that can, in turn, lead to catastrophic system failure, destruction of property and endangerment of life.

A large number of oxygen incidents have been described in the literature, showing both the seriousness and scale of this problem. Between 1982 and 1985, Dicker and Wharton (1988) reported 28 high pressure oxygen incidents, while Fowler and Baxter (2000) detailed several incidents in the UK involving pressurized oxygen in the period 1996 - 1998. Gregson (2008) (of the UK HSE) recorded 158 reported oxygen incidents between 1996 and 2002, including 59 minor injuries, 25 major injuries and 5 fatalities. The NASA Oxygen-Enriched Fire Incidents reporting site (2013) records 119 documents for the period 1984 and 2009. A few of these relate to proposed possible incidents, but the majority detail actual oxygen incidents, with a number containing details of more than 1 event. These primarily occurred in the USA armed forces, hospitals or similar commercial establishments. The site also lists 30 further incidents in Boeing establishments prior to 1992. This is a voluntary recording system and is not therefore indicative of the total number of incidents in the USA, but does show there is in continuing problem. Ahrens (2008) detailed a series of oxygen incidents between 2002 and 2005. These incidents all occurred in the USA, and had been attended and recorder by the US Fire Service attended. He reported an average of 182 fire incidents per year where medical oxygen had been the cause of the fire, resulting in an average of 46 deaths per year. Ahrens also reported there were an average of 1190 thermal burns per year for the period between 2003 and 2006 involving oxygen use, primarily in the home. The NFPA (2014) medical oxygen incident document recoded a selected 40 serious incidents, primarily in the home, involving significant death, injury or financial damage, where medical oxygen was involved. This included 2 fatal fires from 2014. The EIGA Safety Advisory Group (2009), the industry group on European compressed gas safety, listed examples of oxygen incidents stating there have been many more similar incidents.

After an incident has occurred a there is clearly a need to investigate what happened, to learn what went wrong and inform future guidance and safety research. In the case of oxygen systems There are a number of interested parties concerned with oxygen incidents. The process can be confined to one organisation, for example an insurance company consultant, or collaborative. The more serious the incident, the more institutions may have to be involved e.g. an injury or death will result in the involvement of police and, in the UK Health and Safety Executive (HSE) or in the USA the Occupational Safety and Health Administration (OSHA) or one of the organisations they oversee.

In the absence of specific guidance such parties are likely to apply their own procedures for the investigation of such incidents, leading to significant variations with what is recorded and how. Of the incidents listed on the NASA Oxygen-Enriched Fire Incidents reporting site (2013) 12\% mention incorrect material use as the cause, $5 \%$ are attributed to contamination (usually of oil), $4 \%$ to adiabatic compression/pressure shock and 3\% to particle ignition. $54 \%$ do not state a cause, or identify, multiple possible ignition sources due to burn damage and insufficient evidence. Gregson (2008) attributes incidents to and list of four common causes (contamination, fast opening of valves, oxygen enrichment 
from leaks, incompatible materials). Dicker \& Wharton (1998) report 28 incidents, not by cause, but by system location with 39\% occurring in pressure regulators, $21 \%$ during cylinder filling operations, $18 \%$ in pipelines/ manifold and the rest in other equipment such as cylinder valves. Indeed past incident investigation reports carried out by qualified investigators (Benson 2015) show a dramatic lack of standardisation or thoroughness in the information collected. This has resulted in limited and inadequate information to academically assess/ review incidents or conduct further analysis in relation to specific pathways to ignition.

This is in stark comparison to other areas of incident investigation such as house appliance fires where the collection of detailed data has led to databases for academics \& fire professionals to draw on and identify un-safe activities and products (Campbell 2017, Holborn et al 2003) and encourage recalls.

There are currently standards \& guidance that can be used to identify hazards in an oxygen system, or the likelihood of material ignition (BCGA, CGA, EIGA, HSE indg459, BS 5N100-5, ASTM standards G63, G88, and G124) but they exist in different jurisdictions, 'sit' in different industries, and serve different purposes. Only one standard, ASTM G145-08 (2016), specifically advises on oxygen incident investigation but while this also advises on likely hazards, and contributory factors, it does not offer a detailed framework or process guidance that any investigator, especially those relatively unfamiliar with high-pressure enriched oxygen systems, might use. This has contributed to the lack of consistency of approach, and a dramatic shortage of data to enable academics and engineers to identify safety problems (Benson 2015). Therefore a standardised methodology for narrowing the field of, or down selecting, likely ignition sources, would be useful.

The principles of accident investigation, in general, are well documented. Although investigation of the most serious events will have substantial resources available to it, the philosophy behind having a safety culture, regulations and regulatory organisations is to identify problems before they happen, or before they cause serious harm (HSE "Investigating accidents and incidents" guide 2004). In investigating an oxygen incident, it is essential to ensure as much key information as possible can be gleaned from the debris to help identify inappropriate materials, aid in the design of oxygen system components, and most importantly, to prevent similar incidents occurring in the future. It is also essential to record the scientific information for even minor incidents/near misses, since this could give insight into potential root causes of problems in a major incident (of similar root cause) where escalation might make identification of the ignition source difficult or impossible.

Frameworks such as a checklist or flow diagram can aid in making sure key information is identified, and recorded, benefiting the wider investigation process and industry safety information (Mansi 2012). They can also enable the fast and accurate causes of incidents, as well as ensure that useful data was collected for post incident investigation and academic scrutiny. Such a system could readily be applied to the investigation of incidents involving oxygen systems, providing a means of combining the known data on oxygen systems fires/hazards with the principles of incident investigation.

This work details the development and application of incident investigation roadmaps for oxygen systems. These will enable faster and more effective investigation of oxygen incidents, while ensuring key details are recorded and thus benefit post-accident academic analysis. The roadmaps can also 
benefit designers of oxygen systems allowing them to test their designs and operating procedures against specific ignition scenarios.

\section{Theoretical oxygen incident investigation}

\subsection{Oxygen incident causes}

Although the root cause of an incident may be any number of different things including a range of management failures involved in equipment checks and maintenance, staff training etc. the actual sources of ignition for the vast majority of incidents in high pressure enriched oxygen systems are limited to a few events (BS 5N 100-5 2006, ASTM G88 -13). These are identified as:

- Pressure shock and rapid adiabatic compression (accumulated oil/ grease often facilitates this method of ignition).

- Impact by contaminant particles

- Mechanical impact

- Friction in valves

- Cavity resonance

- Electric arcing (e.g. short circuit arcing through sheath)

Electrostatic ignition is also identified in G88 -13 as a hazard. Although Fresh Metal Exposure (FME) is another listed cause in that standard, particularly for materials like aluminium with a high combustion enthalpy, the mechanism will likely be through some form of impact or rubbing and thus is included under those umbrella terms in this work. ASTM G128 / G128M - 15, a guide to controlling hazards and risks in oxygen systems, deals only directly with the first four sources listed for ignition prevention, stating these are the most common.

The accumulation of dust in a system, the contamination by grease not suitable for high pressure oxygen service, poor design or inappropriate component material selection resulting in shearing and particle generation can all contribute to the ignition. For example, some dusts and liquids, particularly organic materials, can self-heat (HSE Offshore Information Sheet No. 11/2008). In practice, there may be multiple failures/causes, mechanisms possibly acting in combination (Yuen et al 1988).

Kindling chain ignition is also a commonly listed cause, but is never the primary cause, with the initial ignition caused by the combustion of other constituent materials or contaminants resulting in a chain of ignitions. An ignition mechanism called "flow friction" was proposed by Beeson et al (2007) (and is mentioned in G88-13) describing it as being caused as a gas flow travels across a polymer, causing erosion and the generation of heat. It is reported by Gallus and Stoltzfus (2006) that a number of fires at NASA have been attributed to this, however Stoltzfus et al (2012) report that it had not been possible to replicate this supposed ignition source, and that other explanations, such as ignition or self-heating of foreign contamination, are more probable. As this has not been shown to be a credible source of ignition this will not be discussed further in this work.

BS EN 1127 (2011) makes reference to a series of possible ignition sources in flammable atmospheres. Although oxygen is not inherently flammable, as it supports combustion, these sources should be referred to. For example, it is clear that the presence of any external heat source, or possibility of a lightning strike, should always be investigated. Some of the sources of ignition named in BS EN 1127 are wholly dependent on the presence of specific types of apparatus, e.g. sources of electromagnetic waves and ionising radiation, and ultrasonic apparatus. They are rare in terms of direct oxygen system ignition and are therefore more likely to be the cause of a kindling chain ignition. While these may be 
possible, and the presence of such apparatus should be explored, the following sections in this work will deal with primarily with the causes that cover the vast majority of incidents, as described in BS $5 \mathrm{~N}$ 100-5 2006, and ASTM G88-13.

\subsection{Potential methodologies - Solutions from Industry}

A number of industries, including chemical and aviation, have developed a variety of tools to check the systems they use. The use of a structure, such as road maps or checklists can significantly improve task success. They do this by reducing the opportunity for human error (Bates et al 2003).

The simplest of these structured approaches is the checklist. A checklist is a formal list used to identify, schedule, compare or verify a group of elements (Federal Aviation Administration 2016) and although it can be as simple as a shopping list, it was first introduced as a safety tool by Boeing in 1935 (Gawande 2009). More recently they have been introduced to the medical industry, for example the WHO surgical safety checklist (Anderson et al 2015). These have resulted in immediate industry improvement and in a significant drop in mortality (Van Klei et al 2012, Anderson et al 2015).

Investigation flow charts and road maps are another structured process providing a defined path to achieve a prescribed goal, but can incorporate multiple courses enabling application to more complex tasks than purely linear processes (ISO 5807 1985). Flow or process charts were first used by Gilbreth and Gilbreth (1921), and have been used for a number of years to detail strategies, processes or paths in technical areas. They have been found extremely useful areas where there may be possible hazardous outcomes, such as nuclear safety engineering (Kempsell et al 2001).

In respect to oxygen Forsyth et al 2003 offers guidance in relation to identifying possible system hazards with a standard forensic system to component to material process, but the work also includes a series of short checklists, ranking importance of hazards, but again this is with a design mind-set and often concentrates on specific components.

For investigation purposes Stephenson (2003) reports road maps have also been employed to combine complex computer technology with traditional investigative methods to investigate digital incidents/ crimes. The NFPA provide numerous flow diagrams in the NFPA 921 (2014) for the purposes of fire investigation in a range of circumstances, and Mansi (2012) has proposed their use to guide general fire investigators at scenes.

Mansi (2012) produced over 200 Fire Investigation Road Maps (FIRMs) to enable a structured way to assess each scene, and to make sure that no possible fire cause could be missed. They take the form of flow diagrams containing boxes that represent actions, decisions to be made, and conclusions that can be drawn. While excellent for training purposes it seems unrealistic that every fire investigator attending a scene very soon after the fire, generally with extremely little information on the nature of the fire, would be carrying a 150 page volume (although the use of technology may in future e.g. an app on a tablet computer makes this more feasible). However, in insurance or Health \& Safety Executive investigations it is far more likely that more specific information on the fire/ explosion would have been given, e.g. an oxygen cylinder has exploded during charging. Under these circumstances having a few road maps to analyse the likelihood of each possible ignition source is a far more realistic 
strategy. They provide a series of logical steps, each assessing the factors that might contribute to ignition.

These are ideal for ignition assessments of oxygen incidents to quickly focus investigation to relevant areas, even where a relative in-expert may be conducting it, due to their easy interpretation and multipath capability, reducing time and resource use. This supported by Kempsell et al (2001) who also list advantages as opportunity for standardisation, for auditing (using numbered boxes), and the possibility to expand or make them part of a wider network or system. While a useful tool, it is advised that they are used as a first stage in, and part of, an overall event or fault analysis to identify the root cause(s) of any incident (Benner 1985).

\section{Development of road maps for the investigation of oxygen incidents}

Based on the extensive literature on the hazards within oxygen systems relating to the causes of fires or explosions in high pressure enriched oxygen it is possible to construct a straightforward series of processes for the investigator of oxygen incidents in order to identify the likely cause of ignition. Following similar processes to those of Weiser et al (2010) first the critical process content has been defined for each ignition cause, i.e. what is required to occur for each separate ignition source to be possible within a high pressure enriched oxygen system, and then diagrammatic formats are compared to assess their usefulness for different scenarios. The systems has then be checked against a real life incident report to check their suitability. Following the example of Mansi (2012) the factors that lead to the ignition are identified using the traditional flow chart gate designation of AND and OR. Factors that must occur to bring about an ignition will come under the AND designation, while where a number of possible factors could bring about the same outcome, contributing towards the ignition, the designation of OR has been applied (See Figures 1 to 7). These are then used in the final flow charts produced in figures 9 to 15 .

\subsection{Identification of critical content for ignition causes in oxygen systems}

\subsubsection{Ignition by pressure shock and adiabatic compression}

When high-pressure valves are opened quickly gas entering the system rapidly can result in heating of materials by two modes. Firstly where high pressure fast flowing gas enters closed-ended components, gas within the component will be adiabatically compressed. Due to the rapid compression the gas heats up, and this hot gas can in turn heat surrounding component materials. Secondly this rapid gas flow can result in a supersonic shock wave, referred to as pneumatic shock, as successive compression waves coalesce, and this shock wave further heats materials in the system. In reality it is difficult to determine which of these modes of heating might have occurred, as they generally happen together (Newton and Steinberg 2009).

Yuen et al (1988) stated that at pressures of 40MPa (approximately 6000psi), temperatures produced by adiabatic compression were up to $1773 \mathrm{~K}\left(1500^{\circ} \mathrm{C}\right)$. The theoretical maximum temperature of rapid pressurisation of a gas can be calculated using:

$$
\frac{T_{f}}{T_{i}}=\left(\frac{P_{f}}{P_{i}}\right)^{\frac{(k-1)}{k}}
$$

where 


$\begin{array}{lll}T_{f} & = & \text { Final temperature } \\ T_{i} & = & \text { Initial temperature } \\ P_{f} & = & \text { Final pressure } \\ P_{i} & = & \text { Initial pressure } \\ k & = & \text { Ratio of specific heats }\left(c_{p} / c_{v}\right) \approx 1.4 \text { for oxygen }\end{array}$

where

$c_{p}=\quad$ Specific heat at a known constant pressure

$c_{v}=$ Specific heat at a known constant volume

This effect has been known to ignite any vapour from accumulated grease and oils in oxygen systems, which then provides the energy for further ignition of the system components. Testing has shown that this mechanism can result in ignition of polymers, and lighter metals/ alloys. The presence of sintered filters can provide an extra hazard because they may contain trapped contaminants prone to ignition, and can be more prone to ignition than bulk materials (Benson 2015, Schadler and Stoltzfus 1993). Newton et al (2000) reported a case of an aluminium medical regulators igniting due to this cause. In this case an oxygen cylinder valve was opened allowing pressurised oxygen into the regulator, which had the flow control turned to the off position. According to Yuen et al (1988) the chances of adiabatic compression can be decreased by the introduction of slow opening valves and heat sinks. These engineering solutions may however result in an increase in cost that many end users might be resistant to accommodating. These points have been incorporated into Figure 1, showing the contributory factors which must be combined (AND gate designation) for ignition to occur, and identifying where a range of factors might lead to the same outcome (OR gate designation).

Figure 1. Factors leading to ignition from pressure shock and adiabatic compression

\begin{tabular}{|c|c|c|c|c|c|c|}
\hline $\begin{array}{c}\text { High Pressure } \\
\text { Enriched } \mathrm{O}_{2}\end{array}$ & $\begin{array}{c}\text { Dead end tube } \\
\text { (+ damage) }\end{array}$ & $\begin{array}{c}\text { High fluid velocity } \\
\text { (driven by pressure } \\
\text { differential) }\end{array}$ & \multicolumn{4}{|c|}{ OR } \\
\cline { 2 - 5 } & Contamination & $\begin{array}{c}\text { Non-metals (low } \\
\text { enough SIT) }\end{array}$ & $\begin{array}{c}\text { Light metals in } \\
\text { dead end section }\end{array}$ & $\begin{array}{c}\text { Sulk metals near } \\
\text { dead end }\end{array}$ \\
\hline
\end{tabular}

\subsubsection{Ignition from impact by contaminant particles}

In flowing oxygen any particles, which enter or break off from within the system, can reach sonic velocities. The impact of these particles is capable of igniting both bulk metals and non-metals. The mechanism of ignition varies. Generally it is the particles that ignite on impact and the energy produced by this ignites further materials. Alternatively if the material being impacted upon is particularly flammable (e.g. polymers, aluminium) it may ignite before the particle. This secondary ignition, capable of igniting heavier bulk metals such as steel (Williams et al 1988), and is a form of 'promoted ignition combustion (Stoltzfus et al 1988). Yuen et al 1988 found that bends and valves were likely to be the most critical ignition sites. Newton et al (2000) also reported particle impact had been responsible for igniting a number of aluminium bodied regulators, often indicated by contaminants in the system, or in attached cylinders. These points have been incorporated into Figure 2.

Figure 2. Factors leading to ignition from particle impact

\begin{tabular}{|c|c|c|c|}
\hline \multicolumn{4}{|c|}{ AND } \\
\hline $\begin{array}{c}\text { High Pressure } \\
\text { Enriched } \mathrm{O}_{2}\end{array}$ & $\begin{array}{c}\text { High fluid } \\
\text { velocity }\end{array}$ & $\begin{array}{c}\text { Particle } \\
\text { contamination }\end{array}$ & $\begin{array}{c}\text { impingement } \\
\text { site }\end{array}$ \\
\hline
\end{tabular}

\subsubsection{Ignition by mechanical impact}


Energy is transferred from kinetic energy, by the impact of an object with a large mass. A material's impact ignition sensitivity can be tested by a number of different methods (Stoltzfus et al 1988). Mechanical impact tests involve dropping a known mass on to a fixed sample from a particular height while particle impact tests involve shooting a particle (either of aluminium or iron) of known size, at a known velocity, on to a material's surface. In both of these tests the atmospheric pressure may be varied to find the maximum working pressure/ concentration for the material. Mechanical impact energy is difficult to determine as it is related to the masses of the materials, their system position and physical parameters such as stress, and deformation and is affected significantly by the direction of impact (Goldsmith 2011). A crude maximum possible impact energy, E, can be calculated where a small mass hits a far larger mass using:

$E=1 / 2 m v^{2}$

where $m$ is the mass and $v$ the velocity, however in the case of particle impact there is also the possibility that the particle will ignite, adding to the energy available to trigger oxidation of the bulk material.

Testing has succeeded in igniting only polymers and the very light metals and alloys (e.g. aluminiumbronze, titanium) and according to McColskey et al (1991) this type of test has not ignited the majority of bulk metals such as Stainless Steels, or brasses. These points have been incorporated into Figure 3.

Figure 3. Factors leading to ignition from mechanical impact

\begin{tabular}{|c|c|c|c|c|c|c|}
\hline \multicolumn{2}{|c|}{ AND } & \multicolumn{3}{|c|}{ OR } \\
\hline $\begin{array}{c}\text { Hressure } \\
\text { Enriched } \mathrm{O}_{2}\end{array}$ & \multicolumn{2}{|c|}{ OR } & \multicolumn{3}{|c|}{} \\
\hline & $\begin{array}{c}2(+) \text { fast } \\
\text { striking bodies }\end{array}$ & $\begin{array}{c}2(+) \text { heavy } \\
\text { striking bodies }\end{array}$ & $\begin{array}{c}\text { Continual } \\
\text { repeated } \\
\text { striking bodies }\end{array}$ & Contamination & $\begin{array}{c}\text { Non-metals } \\
\text { (low enough } \\
\text { SIT) }\end{array}$ & $\begin{array}{c}\text { Light metals in } \\
\text { dead end } \\
\text { section }\end{array}$ \\
\hline
\end{tabular}

\subsubsection{Ignition from frictional heating}

Continuous rubbing, for example, within a valve can cause a build-up of heat energy. The level of heat produced depends on the surface smoothness, the contact area, and the frictional coefficient of the materials involved. Tests for frictional heating take various forms however, they generally comprise of one moving and one stationary part, with materials in each position varied. The ignition probability is tested varying 2 parameters (aside from materials); Pressure; and linear surface velocity. In the case of metals the friction can also reveal clean metal that is not protected by an oxide layer. The rapid oxidation of this new metal can provide the energy for a runaway combustion reaction. Examples of this are a centrifugal compressor rotor rubbing against its casing, or friction in aluminium valves (ASTM G94-05 2014). These points have been incorporated into Figure 4.

\section{Figure 4. Factors leading to ignition from frictional heating}

\begin{tabular}{|c|c|c|c|c|}
\hline \multicolumn{5}{|c|}{ AND } \\
\hline $\begin{array}{c}\text { High } \\
\text { Pressure } \\
\text { Enriched } \mathrm{O}_{2} \\
\end{array}$ & $\begin{array}{l}\text { High velocity/ heavy } \\
\text { load twisting parts } \\
\text { with surface contact }\end{array}$ & \multicolumn{3}{|c|}{ OR } \\
\hline & & $\begin{array}{c}\text { Evidence of } \\
\text { contamination }\end{array}$ & $\begin{array}{l}\text { Non-metals (with a } \\
\text { low enough SIT) }\end{array}$ & Light metals \\
\hline
\end{tabular}

\subsubsection{Ignition by cavity resonance}

The ISO standard 14624-2 (2003) states that acoustic oscillations inside resonant cavities can cause a rapid rise in temperature. If particles are present in the chamber, or if gas velocities are high, this resonance can produce much higher temperatures. This type of ignition has been shown to be particularly ubiquitous where gas flows into a tee, from a throttling device such as a valve (Rosales et al STP 1479 2006). Gas flowing into a tee and out of a branch port can form a resonant chamber at the 
remaining closed port. This has been shown to provide enough energy to ignite polymers, aluminium and stainless steels in testing. The presence of contamination in the system makes this source of ignition particularly likely as this may be ignited if lying in the resonant heating zone. These points have been incorporated into Figure 5.

\section{Figure 5. Factors leading to ignition from cavity resonance}

\begin{tabular}{|c|c|c|c|}
\hline \multicolumn{4}{|c|}{ AND } \\
\hline $\begin{array}{c}\text { High Pressure } \\
\text { Enriched } \mathrm{O}_{2}\end{array}$ & $\begin{array}{c}\text { Dead end } \\
\text { tube }\end{array}$ & $\begin{array}{c}\text { In-line throttling } \\
\text { device (e.g valve) }\end{array}$ & $\begin{array}{c}\text { Evidence of } \\
\text { contamination }\end{array}$ \\
\hline
\end{tabular}

\subsubsection{Ignition by electric arcing and sparking}

Arcing and sparking are similar but not the same. Arcing is the electrical breakdown of a gas causing an on-going plasma stream, while sparking is a momentary electrostatic discharge (via a plasma stream) from one charged surface to an earthed surface. However they are grouped together in this case because they can both result in very high temperature. There are a range of circumstances that can result in electrical ignition of flammable material (BS EN 1127), but generally arcs/sparks form on the opening/closing of circuits (by design or loose connections) or by stray currents. The nature of oxygen system engineering and materials mean that ignition from external arcs/sparks is possible in the presence of high powered systems, ungrounded power supplies, and short-circuits. All types of material, bar only the heavier bulk metal groups, have been shown to ignite by this means in laboratory testing (Beeson et al 2007b). These points have been incorporated into Figure 6.

Figure 6. Factors leading to ignition from electric arcing \& sparking

\begin{tabular}{|c|c|c|c|c|c|c|c|}
\hline \multicolumn{2}{|c|}{ OR } \\
\hline $\begin{array}{c}\text { High Pressure } \\
\text { Enriched } \mathrm{O}_{2}\end{array}$ & \multicolumn{3}{|c|}{ OND } \\
& $\begin{array}{c}\text { Ungrounded } \\
\text { power } \\
\text { supply }\end{array}$ & $\begin{array}{c}\text { High power } \\
\text { systems next to } \\
\mathrm{O}_{2} \text { system }\end{array}$ & $\begin{array}{c}\text { Short-circuited } \\
\text { power supply }\end{array}$ & $\begin{array}{c}\text { Evidence of } \\
\text { contamination }\end{array}$ & $\begin{array}{c}\text { Non-metals } \\
\text { (low enough } \\
\text { SIT) }\end{array}$ & Light metals & $\begin{array}{c}\text { Sintered/thin } \\
\text { bulk metals }\end{array}$ \\
\hline
\end{tabular}

\subsubsection{Static electricity}

According to BS EN 1127 the discharge of charged, insulated conductive parts can easily lead to incendiary sparks. ASTM G88-13 offers the example of an electrically isolated ball valve. Equally nonconducting materials, including most plastics, can develop a potential and discharge. Fast flowing gas with dust contamination, or dry oxygen through hoses, (Rosales et al -STP 1479) can cause a potential to develop on exposed non-conducting surfaces, and 2 non-conductive surfaces can accumulate charge when they rub together. British standard document PD CLC/TR 60079-32-1:2015, which appears to equate oxygen-enriched atmospheres with the more dangerous classifications of flammable atmospheres, recommends dissipative materials, metals bonded to earth, and limiting area of polymer surface, although there is not specific reference to high pressure oxygen in this standard. The risk is increased in dry environments, such as those in oxygen systems. These points have been incorporated into Figure 7.

Figure 7. Factors leading to ignition from static electricity

\begin{tabular}{|c|c|c|c|}
\hline \multicolumn{3}{|c|}{ AND } \\
\hline HP/E O2 & $\begin{array}{c}\text { Non-conducting/ electrically } \\
\text { isolated surface(s) }\end{array}$ & \multicolumn{2}{|c|}{ OR } \\
\hline & & $\begin{array}{c}\text { Charge developed by dust } \\
\text { contamination in oxygen flow }\end{array}$ & $\begin{array}{c}\text { Charge from rubbing } \\
\text { together of 2 surfaces }\end{array}$ \\
\cline { 3 - 4 }
\end{tabular}




\subsection{Investigation tool development}

Using the information defined in section 2.1 there are a number of options for tool development to enable the correct and timely collection and recording of information relating to oxygen system ignition; A checklist, a single roadmap (linking all factors to the ignition causes), or specific roadmaps for each cause. Each had advantages in terms of usefulness of information collected and time saving.

Under time pressured circumstances, where only the minimum resources can be spared, a checklist of crucial information might be a good option. The following list below shows the factors identified as contributing/ causing ignition in oxygen systems:

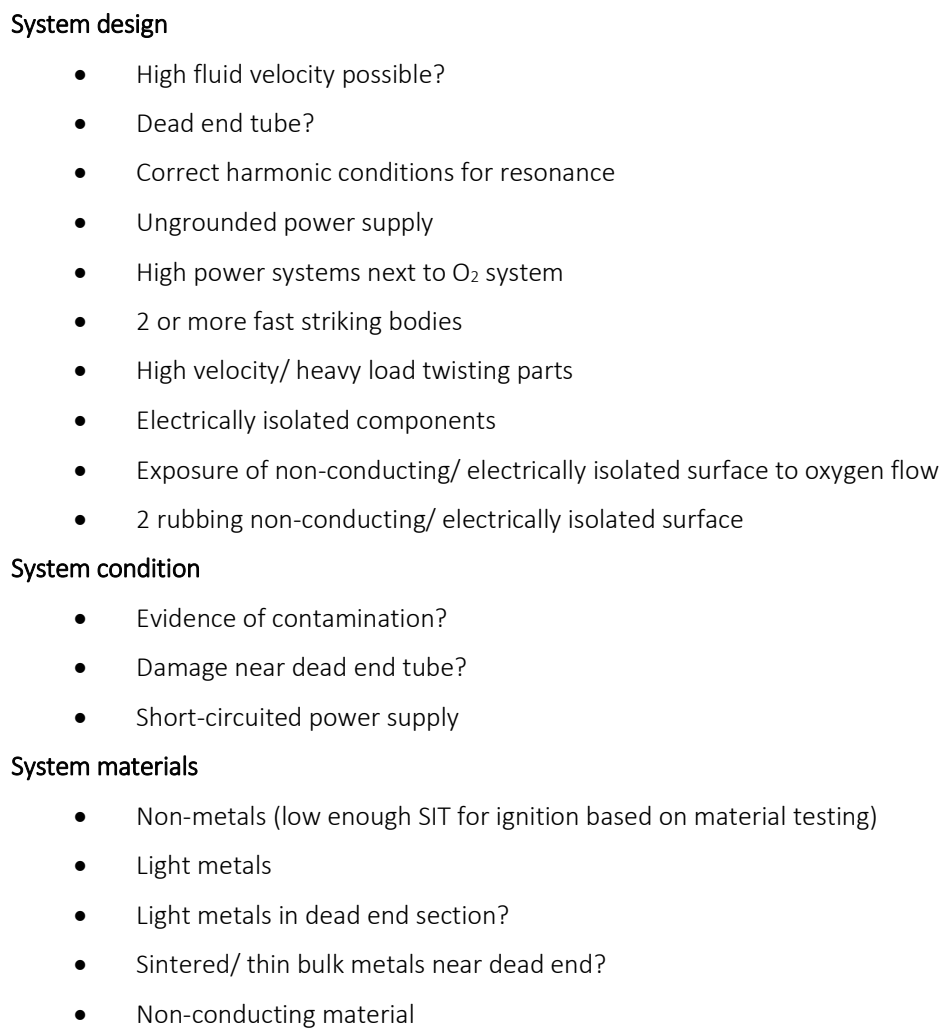

However, this checklist method is extremely limiting and offers no connection to the causes. While time may be limited in an investigation setting, while tick box process might be useful to check information has not been missed, it would therefore be too constrictive for an investigator to evaluate the failed oxygen system, or to explore the alternative and unusual causes listed in BS 1127 if used alone.

A single road map form, as shown in Figure 8, is capable of showing what needs to be examined and collected including the context of the possible ignition mechanisms. This also enables an investigator to see if there were a series of design errors with the system in one diagram. However, as with the checklist, this method has limitations as it fails to allow the investigator to develop a wider view on the system ignition event, particularly when there maybe multiple influencing factors, or something unexpected.

Figure 8. A combination roadmap showing the factors leading to ignition in high pressure enriched oxygen systems 


\begin{tabular}{|c|c|c|c|c|c|c|c|}
\hline Causes & Particle ignition & Pressure shock & $\begin{array}{l}\text { Cavity } \\
\text { resonance }\end{array}$ & $\begin{array}{l}\text { Electric } \\
\text { arc/spark }\end{array}$ & $\begin{array}{l}\text { Mechanical } \\
\text { impact }\end{array}$ & $\begin{array}{l}\text { Frictional } \\
\text { heating }\end{array}$ & $\begin{array}{l}\text { Electrostatic } \\
\text { ignition }\end{array}$ \\
\hline Environment & \multicolumn{7}{|c|}{ High pressure or enriched oxygen environment? } \\
\hline \multirow[t]{10}{*}{ System design } & \multicolumn{2}{|c|}{ High fluid velocity possible? } & & & & & \\
\hline & & \multicolumn{2}{|c|}{ Dead end tube? } & & & & \\
\hline & & & $\begin{array}{c}\text { Correct } \\
\text { harmonic } \\
\text { conditions } \\
\end{array}$ & & & & \\
\hline & & & & $\begin{array}{l}\text { Ungrounded } \\
\text { power supply }\end{array}$ & & & \\
\hline & & & & $\begin{array}{c}\text { High power } \\
\text { systems next to } \\
\mathrm{O}_{2} \text { system }\end{array}$ & & & \\
\hline & & & & & $\begin{array}{l}2 \text { or more fast } \\
\text { striking bodies }\end{array}$ & & \\
\hline & & & & & & $\begin{array}{l}\text { High velocity/ } \\
\text { heavy load } \\
\text { twisting parts }\end{array}$ & \\
\hline & & & & & & & $\begin{array}{l}\text { Electrically } \\
\text { isolated } \\
\text { components }\end{array}$ \\
\hline & & & & & & & $\begin{array}{c}\text { Exposure of } \\
\text { non- } \\
\text { conducting/ } \\
\text { electrically } \\
\text { isolated surface } \\
\text { to oxygen flow }\end{array}$ \\
\hline & & & & & & & $\begin{array}{c}2 \text { rubbing non- } \\
\text { conducting/ } \\
\text { electrically } \\
\text { isolated surface }\end{array}$ \\
\hline \multirow{3}{*}{$\begin{array}{l}\text { System } \\
\text { condition }\end{array}$} & \multicolumn{7}{|c|}{ Evidence of contamination? } \\
\hline & & $\begin{array}{c}\text { Damage near } \\
\text { dead end tube? }\end{array}$ & & & & & \\
\hline & & & & $\begin{array}{c}\text { Short-circuited } \\
\text { power supply }\end{array}$ & & & \\
\hline \multirow[t]{5}{*}{$\begin{array}{l}\text { System } \\
\text { materials }\end{array}$} & & Non-metals & & \multicolumn{3}{|c|}{ Non-metals } & \\
\hline & & Light metals & & \multicolumn{3}{|c|}{ Light metals } & \\
\hline & & $\begin{array}{l}\text { Light metals in } \\
\text { dead end } \\
\text { section? }\end{array}$ & & & & & \\
\hline & & $\begin{array}{l}\text { Sintered/ thin } \\
\text { bulk metals } \\
\text { near dead end? }\end{array}$ & & & & & \\
\hline & & & & & & & $\begin{array}{c}\text { Non-conducting } \\
\text { material }\end{array}$ \\
\hline
\end{tabular}

Finally Individual cause road maps are shown in Figure 9 and Figure 10 (further examples can be seen in Benson 2015). Here the factors contributing to ignition in oxygen systems are limited to the ignition mechanism type. The flow diagram road map form allows each ignition source to be evaluated in turn, listing the key points that need to be considered and recorded to justify any decision. The advantage of having a wider diagram is that it is also possible to put references and reasons for the inclusion of that factor directly on to the diagram. These allow a narrative for ignition causes, but do not encourage a purely tick box mentality to investigation. Rather aiding the investigator to identify the factors that contribute to the most common causes. These diagrams have an additional strength in that they might also be used as guidance to avoid dangerous factors, or combination thereof, when designing, constructing or sourcing components for oxygen systems. I would also be possible to reference particular materials testing methods or standards that an investigator could use to e.g. identify materials. 
Figure 9. Road map to assess the likelihood of pressure shock as a possible ignition source

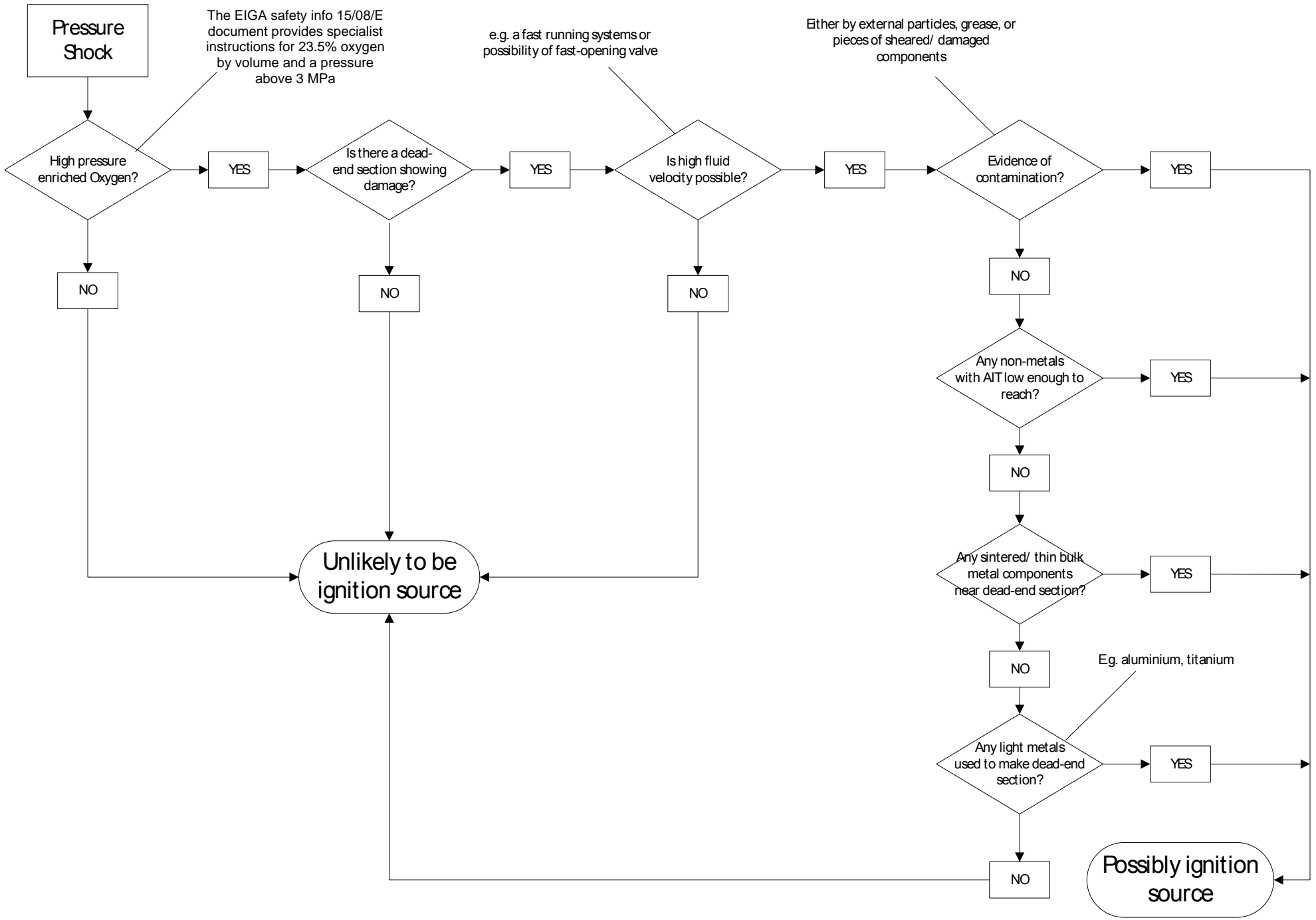


Figure 10. Road map to assess the likelihood of particle impact as a possible ignition source

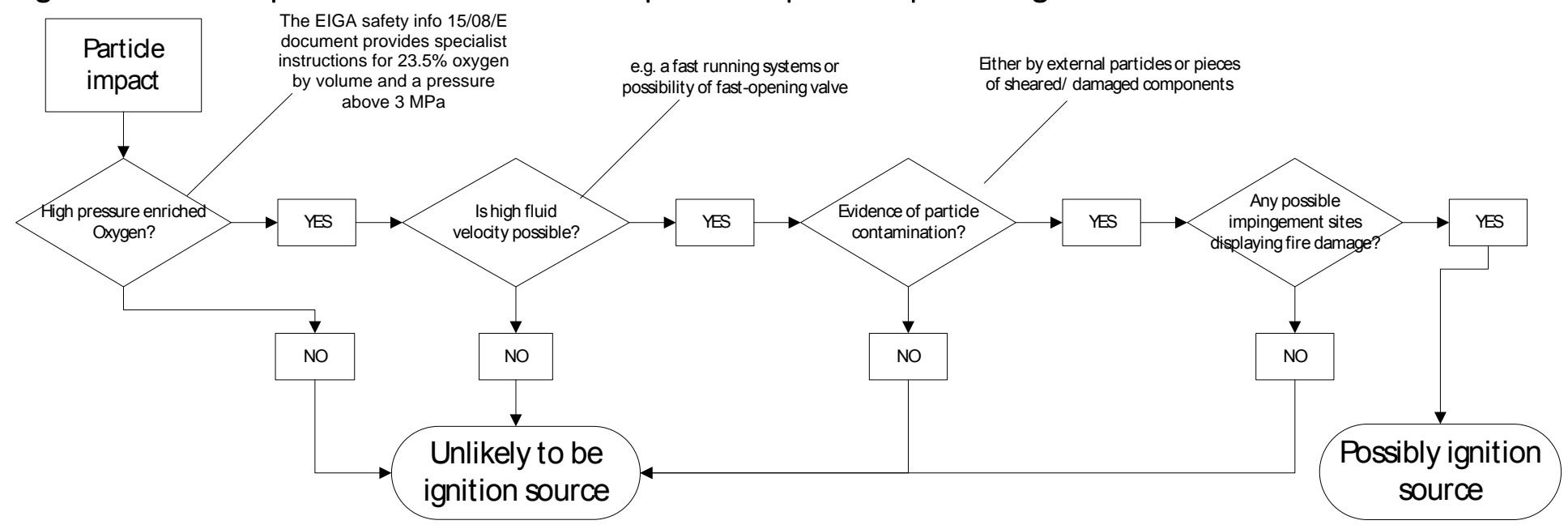




\section{Application of road maps to oxygen incidents}

The road maps developed can be applied to 'real life' incidents, i.e. actual configurations of materials in oxygen systems that have ignited in the past, to enable identification of the likely causes of ignition and collection of information.

Although some assumptions might still be necessary in the absence of all required information, these processes should aid in turning the incident investigation into one based more in scientific reasoning, and to make certain that relevant information is collected should even greater depth investigation be required at a later date. It should also provide greater insight into possible incidents of the future, the importance of material selection, and why knowledge of the physical and thermal properties of the materials involved is also so important. This would then provide a greater database for prediction \& prevention of incidents, and possibly insights into existing or new ignition phenomena.

If this greater database existed it would be possible to perform a quantitative statistical analysis as part of this process. Information on material \& component failure (such as those used in FMECA [Reliability analysis centre 1993]) as well as lengths of service for the system components, could be incorporated into this process. With the relevant data (following a significant number of flammability tests or incidents) it would also be possible to apply probability data to the ignition of materials. It might then be possible to perform an analysis, such as a Bayesian analysis, to determine any ignition hazard issues. Due to the difficulty in testing materials in pure oxygen (limited number of apparatus globally, danger, expense) test data are not currently available in the volume that would enable this type of analysis. Although not their primary role, Figures 9 and 10 might also be used to advise active system designers and installers in industrial plants to check if there is any danger of ignition in their oxygen systems, by following the flow diagrams for the systems they are making. They can be used in a standardised way, and using numbered boxes to allow an audit trail for decisions making. They can also be used as the basis of development for more complex/ expert systems and knowledge banks on oxygen hazards.

The following section contains information on an incident obtained from an in-depth incident component examination report carried out by the Health and Safety Laboratory (Geary 2007a). This incident report is not indicative of general incident issues, but a report of greater depth by HSL. The in-depth investigation was requested by the HSE as this was the fourth in a series of similar incidents to occur.

\subsection{Incident and system}

In February 2007 a PTFE lined oxygen supply hose attached to a cylinder ignited and failed during recharging at Mansfield Mines Rescue Service. There was extensive damage to the hose, as well as evidence of heat damage and fusion to the internal components of an attached bleed valve.

The system was for recharging oxygen cylinders at high pressure. The system is capable of recharging using a 2000 psi loop (13.8 MPa) and a 3000 psi loop (20.7 MPa). The layout of the full system is shown in Figure 11. Several cylinders needed recharging. Following the successful filling of three cylinders, the process of filling a fourth cylinder was begun. Following the opening of the output stop valve, but prior to the opening of the recharge cylinder valve the operator noticed that the flexible 
hose between the two was glowing. This was very quickly followed by the hose rupturing. The oxygen supply was isolated, and the fire extinguished.

The standard system filling procedure was identified by Geary (2006) as good practice due to the gradual rise in pressure in the system, however, investigators ascertained that in reality a full threestage pressurisation process (with the full 3000 psi or $20.7 \mathrm{MPa}$ booster pressure being applied after the cylinder pressures) was only followed by operators for the first cylinder being filled. For subsequent cylinders the hose and attached components would go from ambient pressure (having been bled) to the full booster pressure of 20.7 MPa.

Figure 11. System schematic from HSL report Geary (2007a) showing the components and oxygen flow during recharging of a cylinder which resulted in catastrophic failure

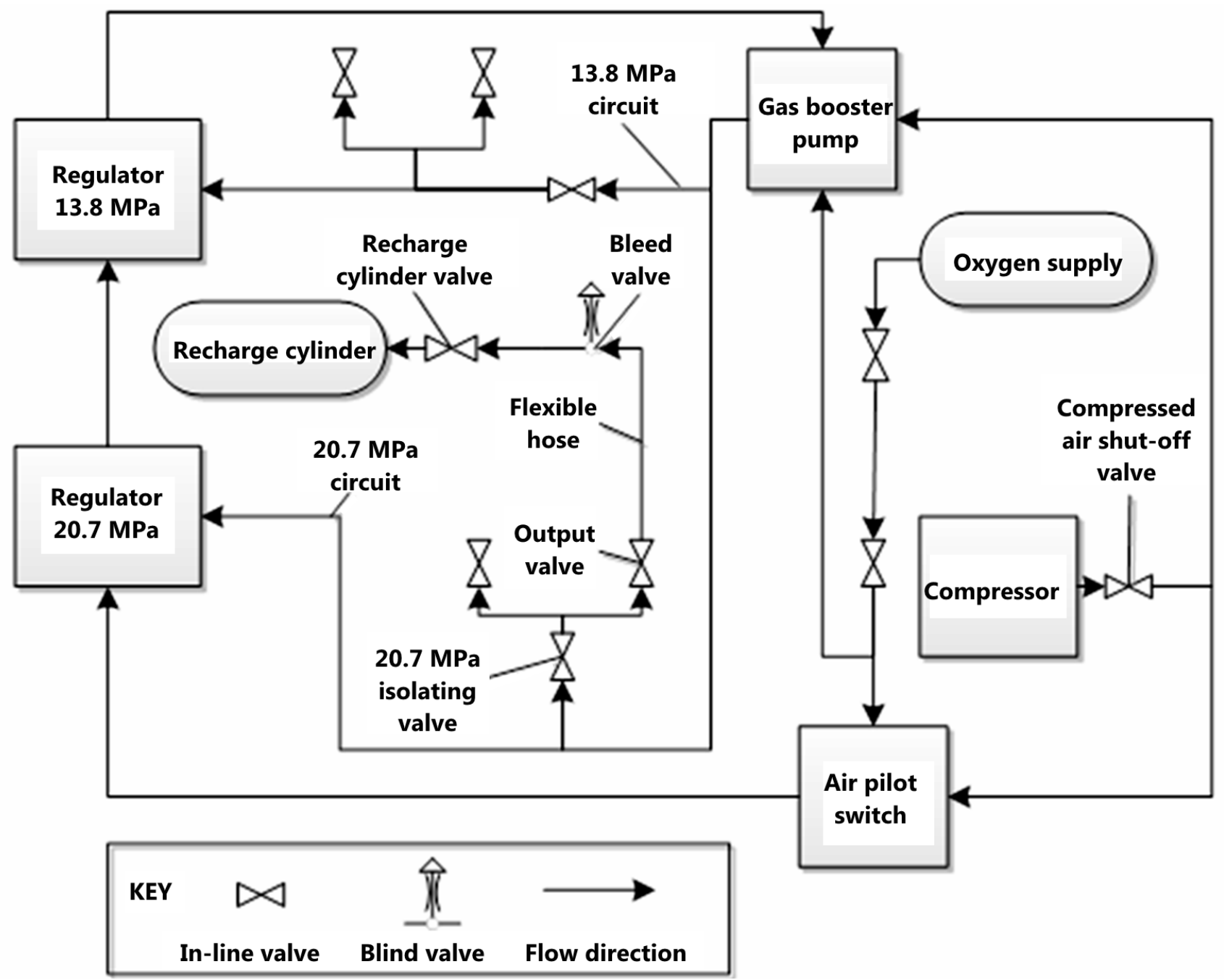

\subsection{System components}

All of the system components were examined by investigators, however, most did not display anything unusual or any indications they may have contributed to the incident, other than by providing the high pressure oxygen. Based on damage and soot deposition the components of interest were between the system output valve and the cylinder valve, focused in 2 components; the oxygen supply hose, and the bleed valve. 
The metallic ends of the flexible PTFE lined hose burst in the incident, each with some of the hose still attached (180mm and $10 \mathrm{~mm}$ respectively). The hose ends were made of leaded 60/40 brass, while the outer braid sheathing (external diameter, $11 \mathrm{~mm}$ ) and ferrules connecting the hose to the end piece were made from 314 stainless steel. The inner lining of the hose was made of PTFE (external diameter, 8.42-8.51 mm, thickness, 0.957-0.999 mm). At the system pressure of 20.7 MPa the SIT of PTFE has been calculated to be approximately $760 \mathrm{~K}$ (Benson et al 2016). The stainless steel and brass materials have melting points (which can be used as probable SIT values re. Abbud-Madrid et al 1993) of $1783 \mathrm{~K}$ and $1173 \mathrm{~K}$ respectively and extinguishing pressures (EPs) of 6.9 and 68.9MPa respectively (NASA NSS 1740.15 1996). The original hose was approximately $630 \mathrm{~mm}$ including the fittings.

The hose showed evidence of 2 failure events. Firstly the hose tube liner and braiding had split and broken off approximately $10 \mathrm{~mm}$ from the hose connector piece at the bleed valve end. The lack of combustion evidence suggests this was an overpressure issue. Further along the tube there were a number of areas that showed evidence of melting and incomplete combustion of the stainless steel braiding. A significant amount of the PTFE had burned away. Where the tube liner was still in place, the liner showed evidence of internal thinning to an average thickness of $0.43 \mathrm{~mm}$.

A diagram of the oxygen supply hose bleed valve unit, including the complex internal parts, can be seen in Figure 12. There is a central bore running through the main valve body, in which there is a small ball bearing (which acts a check valve, preventing gas from the cylinder moving past this point), a sintered filter to prevent particles from travelling into the system, and a retaining screw with a hollow bore through the centre. The complexity of the valve and series of small parts shown in in Figure 12 demonstrate the difficult nature of incidents involving components that contain multiple small subcomponents.

Figure 12. Aluminium bronze bleed valve produced using detail from Geary (2006), Geary (2007a), \& Geary (2007b)

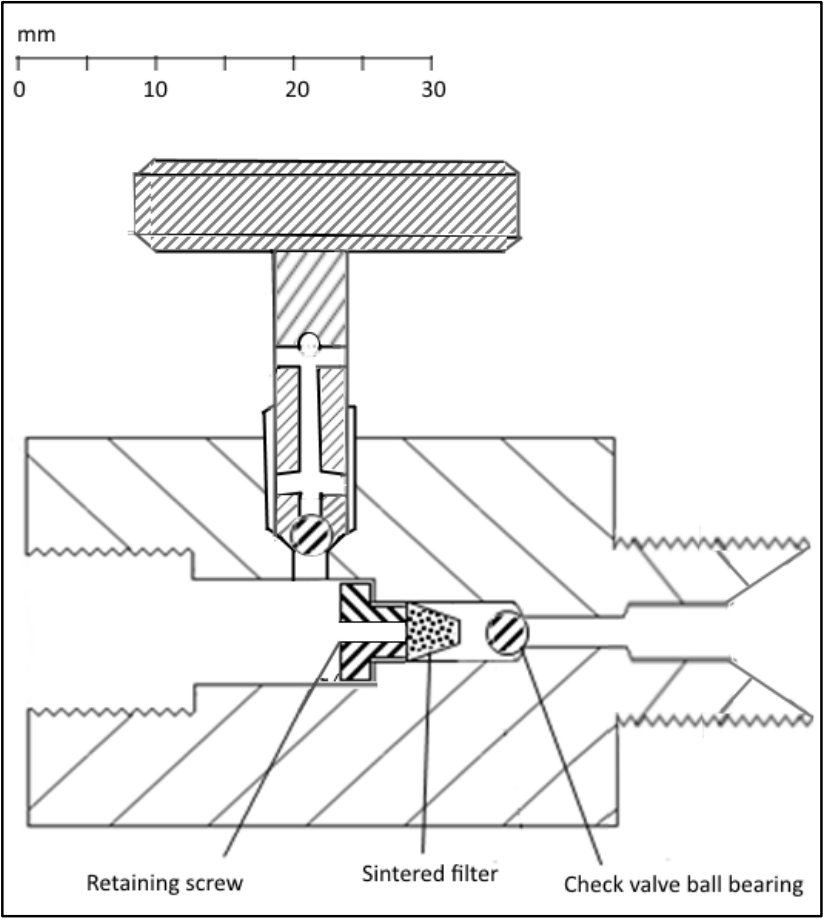


The main valve body is made of aluminium bronze. Although the likely ignition temperature of the bulk material is over 2000K, over the melting temperature of Aluminium Oxide (Abbud-Madrid et al 1993), this material is not regarded as being suitable for high pressure enriched oxygen service as ignition occurs at pressures as low as 3.5 MPa (BS 5N 100-5). The internal component parts in the direct gas stream are made of bronze (most likely tin bronze from debris analysis). Tin Bronze has a melting temperature (lower limit) of approximately $1127 \mathrm{~K}$ (Matweb.com 2017) and an extinguishing pressure of at least 68.9 MPa (NASA NSS 1740.15. (1996)), although small components have a higher surface area to mass ratio making the materials more prone to ignition (Schadler and Stoltzfus 1993).

There is also a bore at right angles with the main central bore. This contains a metal shaft which can be screwed in and out using the wheel at the top. At the base of the shaft is another ball bearing. This section of the component acts as the bleed valve for the charging hose.

The damage in the bleed valve was contained in the main central bore. The retaining screw was undamaged however the sintered filter had broken into pieces and showed signs of oxidation. Some of the check valve ball bearing was left behind, although the mass of debris has not been defined. The shaft and ball bearing in the bleed valve mechanism had not been damaged, but were covered in soot.

Table 1 The component parts of a bleed valve involved in a catastrophic failure event in 2007

\begin{tabular}{llll}
\hline Component part & Dimensions & $\begin{array}{l}\text { Approximate } \\
\text { Mass g }\end{array}$ & Approx. SIT K \\
\hline Valve body (Al Bronze) & $\begin{array}{l}5.7 \mathrm{~mm} \text { long } \\
(4.3 \mathrm{~mm} \text { body) }\end{array}$ & $200-250$ & 2072 \\
\hline Retaining screw (314 SS) & $\begin{array}{l}\text { Approx. 7mm diameter } \\
\text { \& 5mm length }\end{array}$ & 5 & 1783 \\
\hline Sintered filter (Tin bronze) & Approx. 4.4 mm & 1 & 1127 \\
& & 1 & powder $=655$ \\
\hline Check valve ball bearing (Tin bronze) & $3.2 \mathrm{~mm}$ diameter & 1127 \\
\hline Bleed valve shaft (314 SS) & Approx. 5mm diameter & 4 & 1783 \\
\hline Bleed valve ball bearing (Tin bronze) & $3.2 \mathrm{~mm}$ & 1 & 1127 \\
\hline SS Stainless Steel & & & \\
\hline
\end{tabular}

SS = Stainless Steel

\subsection{Ignition mode analysis using Road map process}

The physical evidence has been compared to the processes outlined in investigation road maps (see Figure 9 and Figure 10, and Benson 2015 for examples), and these have been used to assess the likelihood of ignition modes.

Briefly, the lack of electrical, fast moving parts or rubbing parts next to the areas of damage imply static, electrical, mechanical impact and frictional heating can be dismissed as probable cause of ignition. For cavity resonance to occur the main requirement is an area of stagnation (such as a dead ended off shoot from the system) where contaminants might accumulate (figure 6.7). Although the system does contain a $T$ junction with such a stagnation point, this is beyond the region that was pressurised (i.e. the wrong side of the cylinder valve) and does not show any evidence of heat damage or soot. Thus cavity resonance can also be dismissed as a likely possible cause of ignition.

The possibility of particle Impact was assessed using Figure 10, shown in Table 2: 
Table 2 Analysis of the presence of factors contributing to particle Impact ignition

\begin{tabular}{|c|c|}
\hline $\begin{array}{l}\text { High pressure/ } \\
\text { enriched } \\
\text { oxygen? }\end{array}$ & $\begin{array}{l}\text { The system pressure exposure has been identified by investigators as } 20.7 \mathrm{MPa} \\
\text { pure oxygen which is well in excess of the } 23.5 \% \text { and } 3 \mathrm{MPa} \text { requirements for the } \\
\text { system to be regarded as high pressure enriched oxygen. }\end{array}$ \\
\hline $\begin{array}{l}\text { High fluid } \\
\text { velocity? }\end{array}$ & $\begin{array}{l}\text { The output stop valve has been identified as being fast opening (hence the } \\
\text { immediate exposure to the gas pressurised to } 20.7 \mathrm{MPa} \text { ). Assuming the pressure } \\
\text { in the hose was } 0.101 \mathrm{MPa} \text { the possible gas velocity can be estimated, using } \\
\text { equation } 5.53 \text { from ASTM G88-13 (2013), as being over } 1300 \mathrm{~m} / \mathrm{s} \text { (assuming } \\
\text { isentropic flow). Although this is speed is well above the maximum speed of Mach } \\
0.7 \text {, the criteria for applicability of this equation (Perry and Chilton } 1973 \text { ), it is a } \\
\text { good indication that the flow speed would be very fast, and well above the } 45 \mathrm{~m} / \mathrm{s} \\
\text { required for particle impact ignition. Both of these points show that fast fluid } \\
\text { flow was possible. }\end{array}$ \\
\hline $\begin{array}{l}\text { Evidence of } \\
\text { particle } \\
\text { contamination? }\end{array}$ & $\begin{array}{l}\text { Some hydrocarbon contamination on the outside of the hose was identified by } \\
\text { investigators but there was no organic contamination inside the pipe. Only a very } \\
\text { small amount of inorganic dirt was identified using swabs in the output valve. } \\
\text { The presence of a check valve and sintered filter to prevent contamination by } \\
\text { larger particles from recharging cylinders suggests that this type of } \\
\text { contamination, though not impossible, would be unlikely. }\end{array}$ \\
\hline $\begin{array}{l}\text { Possible } \\
\text { impingement } \\
\text { sites }\end{array}$ & $\begin{array}{l}\text { The hose used for recharging was flexible meaning it is possible for the hose to } \\
\text { have presented a face to the onward flow for a particle impact situation to be } \\
\text { possible. Also the check valve ball bearing was directly in the main gas stream } \\
\text { with the sintered filter immediately behind it. All three of these items showed a } \\
\text { significant level of damage. }\end{array}$ \\
\hline $\begin{array}{l}\text { Assessment of } \\
\text { ignition mode }\end{array}$ & $\begin{array}{l}\text { Although it is not possible to completely rule it out the lack of serious particulate } \\
\text { contamination identified in the system makes particle impact unlikely }\end{array}$ \\
\hline
\end{tabular}

The possibility of Adiabatic heating/ pressure shock was assessed using Figure 9, and is shown in Table 3:

Table 3. Analysis of the presence of factors contributing to adiabatic/ pressure shock ignition

\begin{tabular}{ll}
\hline $\begin{array}{l}\text { High pressure/ } \\
\text { enriched }\end{array}$ & $\begin{array}{l}\text { Again, a system pressure of 20.7 MPa pure oxygen has been identified by } \\
\text { investigators, which is well in excess of the 23.5\% and 3 MPa requirements for } \\
\text { the system to be regarded as high pressure enriched oxygen. }\end{array}$ \\
\hline $\begin{array}{l}\text { Dead end } \\
\text { tubing with/ } \\
\text { near damage }\end{array}$ & $\begin{array}{l}\text { The 'output stop valve' had been opened while the recharge cylinder valve at the } \\
\text { end of the supply hose had not been opened making the tube dead-ended. }\end{array}$ \\
\hline $\begin{array}{l}\text { High fluid } \\
\text { velocity }\end{array}$ & $\begin{array}{l}\text { As mentioned previously the fast opening valve (hence the immediate exposure } \\
\text { to a pressure of 20.7 MPa) and possible rapid pressure rise from 0.101 MPa to } \\
\text { 20.7 MPa. The possible gas velocity can be estimated, using equation 5.53 ASTM } \\
\text { G88-13 (2013), as being well over the 30-45 m/s threshold for possible particle } \\
\text { impact ignition. Fast fluid flow was, therefore, possible. }\end{array}$ \\
\hline $\begin{array}{l}\text { Evidence of } \\
\text { contamination }\end{array}$ & $\begin{array}{l}\text { Hydrocarbon contamination on the outside of the hose was identified by } \\
\text { investigators but did not identify any particulate beyond that produced by the fire } \\
\text { in the incident. The presence of a check valve and sintered filter to prevent } \\
\text { contamination from recharging cylinders suggests that this type of } \\
\text { contamination, though not impossible, would be unlikely. }\end{array}$ \\
\end{tabular}




\begin{tabular}{|c|c|}
\hline $\begin{array}{l}\text { Possible } \\
\text { impingement } \\
\text { sites } \\
\end{array}$ & Dead end of closed valve, and multiple components in gas stream. \\
\hline $\begin{array}{l}\text { Non-metals/ } \\
\text { sintered metals/ } \\
\text { Light metals at } \\
\text { dead end point }\end{array}$ & $\begin{array}{l}\text { In the area of ignition the only polymeric material is the PTFE liner of the filling } \\
\text { hose. Using equation } 4.14 \text { (Benson 2015) the SIT of PTFE can be estimated to be } \\
\text { approximately } 763 \mathrm{~K} \text {. Again assuming atmospheric pressure in the system before } \\
\text { pressurisation, and using information in Newton and Steinberg (2009), the } \\
\text { temperature of an ideal gas can be estimated as being between } 1339 \mathrm{~K} \text { (due to } \\
\text { isentropic compression) and } 11568 \mathrm{~K} \text { (due to shock factors). Although these } \\
\text { temperatures would be momentary they are well above the SIT of the PTFE } \\
\text { component. There is a bronze filter directly in the gas stream. Although bronze } \\
\text { generally has good oxygen service properties (e.g. Melting point of } 1127 \text { and } \\
\text { extinguishing pressure of } 68.9 \mathrm{MPa} \text { for tin bronze) the high surface area to mass } \\
\text { ratio may lessen the resistance to ignition and can be a site of build-up of } \\
\text { contaminant material. The bleed valve body has been identified as being made } \\
\text { from Aluminium bronze. Any components made of aluminium or similar light } \\
\text { metals are more susceptible to ignition than heavier iron or copper based } \\
\text { materials. }\end{array}$ \\
\hline
\end{tabular}

Based on the evidence available, and these analyses, all of the requirements for an adiabatic compression/ shockwave ignition were present making this the most likely source of ignition.

\section{Conclusions}

The flow diagram road map approach has been developed \& demonstrated to identify probable or possible ignition sources in oxygen systems, even in environments where time and access to evidence may be limited. These diagrams benefit industry allowing easy interpretation of complex environments with a range of paths for relative in-experts. This allows collection of data, imperative for any post-event analysis, in a timely and reliable manner. The data can then be used academically for meta-studies on hazard likelihood, and to identify new hazards. The roadmaps can also benefit designers of oxygen systems allowing them to test designs and operating procedures against specific ignition scenarios.

\section{Funding:}

This work was supported by the Ministry of Defence and Harrier Jaguar Survival IPT.

\section{References}

Abbud-Madrid, A, Branch, MC, Feierisen, TJ, and Daily, JW (1993). Ignition of bulk metals by a continuous radiation source in a pure oxygen atmosphere. Flammability and sensitivity of materials in oxygen-enriched atmospheres: V6, ASTM STP 1197, Janoff, Stoltzfus, Ed, American Society for Testing and Materials, Philadelphia. P211-222.

Ahrens, M (2008). Fires and burns involving home medical oxygen. NFPA Fire analysis and research division report. Available at http://wiki.nasa.gov/oxygen-fire-incidents/files/2013/05/Fires-and-Burns-InvolvingHome-Medical-Oxygen-Marty-Ahrens-NEPA-08-2008.pdf. Last accessed 09/06/15 
Anderson, M, Fitzgerald, M, Martin, K, Santamaria, M, Arendse, S, O’Reilly, G, \& Marasco, S (2015). A procedural check list for pleural decompression and intercostal catheter insertion for adult major trauma. Injury, 46(1), 42-44.

ASTM G124-10 (2010) Standard test method for determining the combustion behaviour of metallic materials in oxygen-enriched atmospheres. ASTM International, West Conshohocken, PA.

ASTM G128 / G128M - 15 (2015). Standard Guide for Control of Hazards and Risks in Oxygen Enriched Systems. ASTM International, West Conshohocken, PA.

ASTM G145-08 (2016) Standard Guide for Studying Fire Incidents in Oxygen Systems. ASTM International, West Conshohocken, PA.

ASTM G63- 15 (2015) Standard guide for evaluating non-metallic materials for oxygen service. ASTM International, West Conshohocken, PA.

ASTM G88-13 (2013) Standard guide for designing systems for oxygen service. ASTM International, West Conshohocken, PA.

ASTM G94-05 (2005) Standard guide for evaluating metals materials for oxygen service. ASTM International, West Conshohocken, PA.

Bates, DW and Gawande, AA. (2003). Improving Safety with Information Technology. New England Journal Medicine 348, 2526-2534

Beeson, HD, Smith, SR, Stewart, WF (2007). Safe use of oxygen and oxygen systems 2 nd Ed. Chapter 2: Oxygen system ignition mechanisms. American Society for the Testing of Materials. West Conshocken PA. ISBN 978-0-8031-4470-5

Beeson, HD, Smith, SR, Stewart, WF (2007). Safe use of oxygen and oxygen systems 2nd Ed. Chapter 3: Materials Information Related to Flammability, Ignition, and Combustion. American Society for the Testing of Materials. West Conshocken PA. ISBN 978-0-8031-4470-5

Benner (1985). Rating accident models and investigation methodologies. Rating accident models and investigation methodologies. Journal of safety research, 16(3), 105-126.

Benson, C. M., Bishop, A. M., Ingram, J. M., Phillips, R., \& Nolan, P. F. (2016). The development of a model for the prediction of polymer spontaneous ignition temperatures in high pressure enriched oxygen across a range of pressures and concentrations. Journal of Loss Prevention in the Process Industries, 44, 369-379.

Benson, CM (2015). Investigations into Incidents involving the kindling chain of materials in high-pressure oxygen atmospheres. PhD thesis. London South Bank University, UK.

Bergman, D, Davis, C, Rigby, B. (2007). International comparison of health and safety responsibilities of company directors. Research Report 535. Health \& Safety Executive. Available at http://www.hse.gov.uk/research/rrpdf/rr535.pdf. Last accessed 09/06/15.

Bradley, PL, Baxter, A (2002). Fires, explosions and related incidents at work in Great Britain in 1998/9 and 1999/2000. Journal of loss prevention in the process industries. V15, 15, p365.

British standard document PD CLC/TR 60079-32-1:2015 Explosive atmospheres. Electrostatic hazards, guidance. BSI

BS 5N 100-5 (2006). Aircraft oxygen systems and equipment - Part 5: Guide to fire and explosion hazards associated with oxygen, including handling, storage and replenishment. BSI

BS EN 1127 (2011). Explosive atmospheres. Explosion prevention and protection. Basic concepts and methodology. BSI 
Campbell, R (2017). Electrical Fires. National Fire Protection Association. http://www.nfpa.org//-

/media/Files/News-and-Research/Fire-statistics/Major-Causes/osHomeElectricalFires.pdf. Published March 2017. Last accessed 08/12/2017.

Dicker, DWG, Wharton, RK. (1988) A review of incidents involving the use of high-pressure oxygen from 1982 to 1985 in Great Britain, Flammability and sensitivity of materials in oxygen-enriched atmospheres: V3, ASTM STP 986, DW Schroll, Ed, American Society for Testing and Materials, Philadelphia. p318 - 327. EIGA Safety Advisory group (2009). Newsletter 87/09/E. EIGA.

Federal Aviation Administration (2016). Section 12: Aircraft Checklists for 14 CFR Parts 121/135 iFOFSIMSF Forsyth, ET (2012) WHA characteristic element of common ignition mechanism. Available at Http://www.wendellhull.com/content/files/Characteristic_Elements_Ignition_Mechanism s.pdf. Last accessed 26/03/2015

Fowler, AHK, Baxter, A (2000). Fires, explosions and related incidents at work in Great Britain in 1996/7 and 1997/8. Journal of loss prevention in the process industries. V13, 16, p547.

Gallus, TD, Stoltzfus, JM (2006). Flow Friction Fire History and Research. Flammability and sensitivity of materials in oxygen-enriched atmospheres V11, ASTM STP 1479. D. Hirsch, D, Zawierucha, R, Steinberg, T, Barthelemy, H, Ed. American Society for Testing and Materials. Philadelphia. p151-164

Gawande, A (2009). The Checklist Manifesto--How To Get Things Right. Pp224.Metropolitan Books, New York. ISBN-13: 978-0805091748

Geary, EA (2006). Failed O2 hose and cylinder-Rawdon. Report MM/06/17. Health and Safety Laboratory Geary, EA (2007a). Examination of failed O2 hose at Mansfield mines rescue service. Report MM/07/13. Health and Safety Laboratory

Geary, EA (2007b). Examination of failed O2 hose from Rawdon mines rescue service. Report MM/07/20. Health and Safety Laboratory

Gilbreth, FB, Gilbreth, LM (1921). Process Charts-first steps in finding the one best way. American Society of Mechanical Engineers (ASME), New York, NY.

Goldsmith, W. (2001). Impact. Courier Corporation. New York.

Gregson, M (2008) HSE Discipline Information Note CD5/056. Health and Safety Executive. Available at http://img2.timg.co.il/forums/1_123612579.pdf. Last accessed 11/06/15.

Holborn, PG., Nolan, PF., \& Golt, J. (2003). An analysis of fatal unintentional dwelling fires investigated by London Fire Brigade between 1996 and 2000. Fire Safety Journal, 38(1), 1-42.

HSE Investigating accidents and incidents guide (2004). Available at http://www.hse.gov.uk/pubns/hsg245.pdf. Last accessed 01/02/2017

HSE Offshore Information Sheet No. 11/2008 Contaminated lagging and self-heating. Available at http://www.hse.gov.uk/offshore/infosheets/is11-2008.pdf. Last accessed 01/02/2017

Huang, H, Li, N, Weng, Q (2009). Analysis of 38 accidents and the investigation of safety management about medical hyperbaric oxygen chamber in our country.

Chongqing Medical Journal. V08.

Injury, Volume 46, Issue 1, January 2015, Pages 42-44, A procedural check list for pleural decompression and intercostal catheter insertion for adult major trauma, M. Anderson, ,M. Fitzgerald, K. Martin, M. Santamaria, S. Arendse, G. O’Reilly, de V. Smit, U. Orda, S. Marasco

ISO 14624-2 (2003) Space systems - Safety and compatibility of materials. Part 2. Determination of flammability of electrical wire insulation and accessory materials. Geneva: ISO 
ISO 5807 (1985). Information processing -- Documentation symbols and conventions for data, program and system flowcharts, program network charts and system resources charts. Geneva: ISO

Kelly, E, Hardy, R, Hall, EA, McDonald, J, Turner, M, Rivers, J, Jones, H, Nolan, JP, Cook, TM, Henrys, P (2013). Fire on an intensive care unit caused by an oxygen cylinder. Volume 68, Issue 1, pages 102-104, January 2013

Kempsell, ID, Wakem, MJ, Fairclough, MP, \& Ingram, JM (2001). Hydrogen explosions - an example of hazard avoidance and control. Institution of Chemical Engineers symposium series V148, p523-540. Institution of Chemical Engineers.

Mansi, P (2012). Fire investigation roadmaps and decision trees to assist fire causation identification and improve arson prosecutions. PhD thesis. London South Bank University UK

Matweb (2017). Available at

http://www.matweb.com/search/datasheet.aspx?matguid=558f2c0231c840339b8056ffb747b2c7\&ckck=1. Last accessed 01/02/2017

McColskey JD, Reed, RP, Simon, NJ, Bransford, JW (1991). Recommended changes in ASTM test methods D2512-82 and G86-84 for oxygen compatibility mechanical impact tests on metals. Flammability and sensitivity of materials in oxygen-enriched atmospheres: V5, ASTM STP 1111 Stoltzfus, Mcllroy. Ed, American Society for the Testing of Materials, Philadelphia. P126 - 153.

NASA NSS 1740.15. (1996). Safety standard for Oxygen and Oxygen systems. Guidelines for Oxygen System Design, Materials Selection, Operations, Storage, and Transportation

NASA Oxygen-Enriched Fire Incidents reporting site (2013). Available at http://wiki.nasa.gov/oxygen-fireincidents/wiki/home/. Last accessed 11/06/15.

Newton, B, and Steinberg, T (2009). Adiabatic compression testing- part 1: Historical development and evaluation of fluid dynamic processes including shock-wave considerations. Journal of ASTM International. V6, 18 (September 2009).

Newton, BE, Wilson, DB, Stradling, JS (2000). Potential ignition mechanisms of Buna N O-rings in liquid oxygen. Flammability and sensitivity of materials in oxygen enriched atmospheres: V9, ASTM STP 1395 Steinberg, Newton, and Beeson. Ed, American Society for the Testing of Materials, West Conshocken, PA, 2000. P207 - 223.

NFPA (2014). Selected Published Incidents Involving Medical Oxygen. Fire Analysis and Research Division report. Quincy, MA National Fire Protection Association.

NFPA 921 (2014). Guide for fire and explosion investigations. NFPA.

Perry, RH and Chilton, $\mathrm{CH}$ (1973). Chemical Engineers Handbook, 5rd Ed. Section 5-8: Flow measurement. McGraw Hill, New York. ISBN 10: 0070494789

Reliability Analysis Centre (1993). Failure Modes \& Effects Criticality Analysis (FMECA) AD-278e508; CRTAFMECA; Concurrent Engineering Series. United States DOD Information Centre.

Rosales, KR, Shoffstall, MS, Stoltzfus, JM, (2007). Guide for Oxygen compatibility assessments on oxygen components and systems. NASA report TM-2007-213740

Schadler, JL, and Stoltzfus, JM (1993). Pressurized flammability limits of selected sintered filter materials in high-pressure gaseous oxygen, Flammability and sensitivity of materials in oxygen-enriched atmospheres: V6, ASTM STP 1197, Janoff, Stoltzfus, 143 Ed, American Society for testing and materials, Philadelphia 1993. P119- 132

Stephenson, P (2003), A comprehensive approach to digital incident investigation. Information Security Technical Report, V 8, I 2, June 2003, p42-54, 
Stoltzfus, JM, Gallus TD, and Sparks K (2012). Flow friction or spontaneous ignition. Flammability and sensitivity of materials in oxygen-enriched atmospheres: V13, ASTM STP 1561, Samuel, D, Steinberg, T, Ed, American Society for Testing and Materials, Montreal.

Stoltzfus, JM, Homa, JM, Williams, RE, and Benz, FJ, (1988), ASTM committee G-4 metals flammability test programme: data and discussion, Flammability and sensitivity of materials in oxygen-enriched atmospheres: V3, ASTM STP 986, DW Schroll, Ed, American Society for testing and materials, Philadelphia. p28 - 53 .

Van Klei, WA, Hoff, RG, Van Aarnhem, EE, Simmermacher, RK, Regli, LP, Kappen, TH, van Wolfswinkel, L, Kalkman, CJ, Buhre, WF, and Peelen LM (2012). Effects of the introduction of the WHO "Surgical Safety Checklist" on in-hospital mortality: a cohort study. Annals of surgery V255, 11, p44-49.

Williams, RE, Benz, FJ, Mcllroy, KM (1988). Ignition of steel alloys by impact of low velocity iron/ inert particles in gaseous oxygen. Flammability and sensitivity of materials in oxygen-enriched atmospheres: V3, ASTM STP 986, DW Schroll, Ed, 145 American Society for Testing and Materials, Philadelphia. p72-84

Yuen, WW, Greer, D, Lin, G, and Bryan, C (1988). Modelling of the transient ignition of a nonmetal/ oxygen system by heterogeneous reaction: Effects of oxygen pressure. Flammability and sensitivity of materials in oxygen-enriched atmospheres: V3, ASTM STP 986, DW Schroll, Ed, American Society for Testing and Materials, Philadelphia. p85-104 